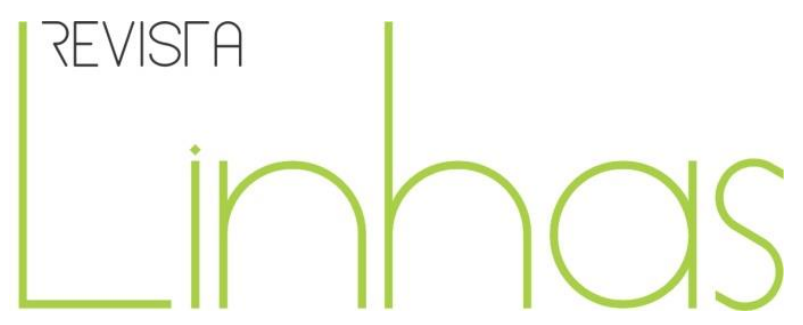

\title{
A experiência educacional e sanitária da Escola Regional de Meriti: modernização e regionalismo num sertão próximo à Capital (1921-
} 1932)

\section{Resumo}

Este artigo analisa a primeira década da Escola Regional de Meriti, instituição educacional privada, criada na vila de Meriti (atual Duque de (axias/RJ), em 1921. As conexões entre os movimentos sanitarista e educacional da década de 1920, na Capital, fizeram surgir a ideia de modernização do Brasil através da criação de uma escola, para cuidar do corpo e do espírito das crianças do sertão. Esse empreendimento, liderado por Armanda Álvaro Alberto, contou com a participação e apoio de intelectuais da Capital Federal, como Edgar Sussekind de Mendonça, Francisco Venâncio Filho, Belisário Penna, Antonio Pacheco Leão, Edgar Roquette Pinto e Alberto Rangel. O conceito de regionalismo presente nos discursos dos participantes da Escola ressaltava a necessidade de levar educação e saúde aos sertanejos brasileiros. Começando pelas crianças, mas também aos responsáveis destas e, por fim, a todos os homens e mulheres do sertão. Assim, eles poderiam crescer fortes, saudáveis e com conhecimentos para que o país alcançasse o progresso. Havia uma perspectiva de manter o sertanejo no seu próprio lugar, sem a necessidade de buscar uma vida melhor nas cidades. E, ao mesmo tempo, o interesse de fazer com que cada região se desenvolvesse de acordo com suas potencialidades. A escolha da vila de Meriti, um sertão próximo à Capital, era a possibilidade de estar em um lugar de fronteira entre o interior e a grande cidade e de que os intelectuais partícipes da escola pudessem construir uma escola no sertão e debater nos círculos intelectuais da Capital.

Palavras-chave: educação; saúde; modernização; regionalismo; sertão próximo.

\author{
Julio Paixão Santos \\ Colégio Pedro II - CPII - Rio de \\ Janeiro/RJ - Brasil \\ juliopaixaosantos@gmail.com
}

\footnotetext{
Para citar este artigo:

SANTOS, Julio Paixão. A experiência educacional e sanitária da Escola Regional de Meriti: modernização e regionalismo num sertão próximo à Capital (1921-1932). Revista Linhas. Florianópolis, v. 22, n. 50, p. 111-140, set./dez. 2021.
} 


\title{
The educational and health experience of the Escola Regional de Meriti: modernization and regionalism in a sertão next to the Capital (1921-1932)
}

\begin{abstract}
This article analyzes the first decade of the Escola Regional de Meriti, a private educational institution, created in the village of Meriti (currently Duque de (axias/RJ) in 1921. The connections between the sanitary and educational movements of the 1920 s in the capital made arise the idea of modernization of Brazil through the creation of a school, to take care of the body and spirit of children in the sertão. This enterprise, led by Armanda Álvaro Alberto, had the participation and support of intellectuals from the Federal Capital, such as Edgar Sussekind de Mendonça, Francisco Venâncio Filho, Belisário Penna, Antonio Pacheco Leão, Edgar Roquette Pinto and Alberto Rangel. The concept of regionalism present in the speeches of the School's participants highlighted the need to bring education and health to Brazilian backlands. Starting with the children, but also those responsible for them and, finally, all the men and women of the sertão. Thus, they could grow up strong, healthy and with the knowledge for the country to make progress. There was a perspective of keeping the sertanejo in their own place, without the need to seek a better life in the cities. And, at the same time, the interest in making each region develop according to its potential. The choice of the village of Meriti, a sertão next to the Capital, was the possibility of being in a place on the border between the interior and the big city and that the participating intellectuals of the school could build a school in the sertão and debate in the intellectual circles of the Capital.
\end{abstract}

Keywords: education; health; modernization; regionalism; sertão Next. 
Cem anos depois, a Escola Dr. Álvaro Alberto ainda existe. Uma raridade em tempos de rapidez, volatilidade, incertezas e liquidez. Criada em 13 de fevereiro de 1921, a Escola Proletária de Meriti pretendia cuidar dos corpos e dos espíritos das crianças de um sertão próximo à Capital Federal. Um ano depois, o nome foi mudado para Escola Regional de Meriti (ERM), na expectativa de que, num futuro, quando estivesse melhor organizada, se chamasse Dr. Álvaro Alberto. A líder da formação desta escola foi Armanda Álvaro Alberto, que desejava homenagear seu pai, dando à Escola o seu nome (ALBERTO, 1921, p. 1-3).

Embora o nome desejado se mantenha, muita coisa mudou entre a Escola Dr. Álvaro Alberto atual e a Escola Regional de Meriti. No passado, havia um grande movimento educacional e sanitário no Brasil, que desejava modernizar o país por meio da criação de órgão públicos e privados. A disseminação de princípios sanitários, a criação de postos de saúde por todo o território e de escolas públicas e privadas eram objetivos importantes num momento em que a população brasileira tinha muitas doenças e era analfabeta.

Nos dias atuais, existe uma rede de saúde pública e de educação pública presente em todas as cidades do país. Contudo, os desafios de garantir educação e saúde de qualidade para todos os brasileiros permanecem. Analisar a Escola Regional de Meriti, seus objetivos, suas práticas, seus problemas e suas soluções nos ajuda a compreender as diferenças e semelhanças entre os objetivos educacionais e sanitários dos intelectuais do início do século XX e os nossos. Olhar para o passado pode ser uma boa alternativa para buscar espaços de experiência que nos levem a pensar e repensar o nosso presente, criando novos horizontes de expectativas.

O objetivo principal deste artigo é analisar a primeira década de atuação da Escola Regional de Meriti, entendendo as conexões entre o movimento sanitarista e o movimento educacional das décadas de 1910 e 1920 presentes na instituição. Através da liderança da professora Armanda Alberto, foi possível reunir diversos médicos educadores e intelectuais, de várias instituições da Capital, em prol de iniciativas educacionais renovadoras. A organização fazia parte de um movimento educacional 
internacional que ficou conhecido como Escola Nova, que pretendia dar mais liberdade às crianças. Nesse sentido, o empreendimento era construído com um repertório diversificado de perspectivas educacionais que vinham da Europa e dos EUA, mas que foram reelaborados a partir das demandas educacionais e sanitárias locais (MIGNOT, 2002).

O nacionalismo militante no contexto brasileiro das décadas de 1910 e 1920 levava diversos intelectuais da Capital a defenderem uma modernização baseada na ideia de rápida superação do atraso brasileiro (OLIVEIRA, 1990). Nessa conjuntura, o sertão era visto como o lugar desse atraso, repleto de ignorância, doença, carência e privações (LIMA, 1999). Na concepção de Armanda e de outros partícipes da Escola, a superação deveria levar em conta não somente uma idealização do que é a nação brasileira, mas também as realidades regionais de cada parte do Brasil (MENDONÇA, 1968, p. 20-22). Assim, não deveria existir uma forma de educação para todo país, mas cada região deveria encontrar sua forma de educar, a partir das necessidades e do ambiente de cada localidade.

O propósito político era manter os sertanejos nos lugares onde estavam, ensinando-os a viver em sua própria região, fazendo com que ela se desenvolvesse. Isso impediria a concentração nas grandes cidades e poderia melhorar a vida dos brasileiros do sertão. O médico Belisário Penna propunha inclusive a distribuição de terras para os "humildes homens da terra", considerando o fato de, segundo ele, "90 \% das famílias brasileiras" não terem "lar próprio nem qualquer trecho de terra" (PENNA, 1931 apud CARVALHO, 1998, p. 163). Logo, a educação e a saúde levadas pela escola deveriam atingir a toda população da localidade: crianças, mães e pais, famílias dos educandos e população local. A Escola era vista não somente como um lugar para instruir as crianças com conhecimentos, mas também como uma instituição que se relacionaria com toda a sociedade local, ajudando-a no seu desenvolvimento.

Para que esse empreendimento fosse levado a cabo por intelectuais da Capital era necessário um ambiente que não estivesse distante da cidade do Rio de Janeiro, mas tivesse características de Sertão. Era necessário um lugar de fronteira entre o mundo da Capital, visto como modernizado, e o mundo do sertão, considerado como atrasado. Essa região foi a baixada do estado do Rio de Janeiro, local próximo à Capital Federal que 
desde o século XVIII foi usado como lugar de passagem para as regiões mineradoras e como terras de cultivo (PEREIRA, 1977, p. 85; ALVES, 2003, p. 40). No século XIX, com a abertura da Estrada Real e das Estradas de Ferro na região, se tornou mais fácil o trânsito entre a baixada e a Capital, gerando a ocupação populacional próxima às ferrovias (FORTE, 1933, p. 60; SOUZA, 2006, p. 63; FRÓES, 1974, p. 31).

No início do século XX, várias obras de saneamento, ações de contenções de doenças e captação de águas foram empreendidas na baixada, que serviu como um lugar de experiências para os médicos da Capital. A partir da observação dos fenômenos naquela localidade foi possível pensar na organização das medidas sanitárias nas regiões sertanejas do Brasil. Dessa forma, era de conhecimento do círculo de médicos do Rio o caminho para a baixada e as condições sanitárias locais. Essa perspectiva da baixada como lugar de experiência se repetiria com a Escola Regional de Meriti, que tinha como diretora a filha de um importante médico da Capital, além de outros médicos que apoiavam a iniciativa (SANTOS, 2008).

Na primeira parte do texto, abordarei o conceito de baixada do Rio de Janeiro como sertão próximo à Capital, procurando entender os motivos que levaram a Escola Regional de Meriti para essa localidade. Na segunda parte, analisarei os movimentos educacionais e sanitários da década de 1910 e início da década de 1920, buscando compreender o contexto de criação da Escola. Na terceira parte, analisarei as relações entre os conceitos de modernização e de regionalismo presentes na criação da instituição educacional. Na quarta parte, explicitarei a experiência educacional da Escola, que buscava cuidar dos corpos e dos espíritos no sertão próximo. Na quinta parte, procurarei demonstrar como a experiência da ERM se tornou no discurso do movimento educacional brasileiro um exemplo a ser seguido. Por fim, nas considerações finais, reunirei elementos que permitem perceber a importância dos estudos sobre esta escola ainda hoje.

\section{Baixada do Estado do Rio de Janeiro como sertão próximo à Capital}

A baixada do Estado do Rio de Janeiro foi ao longo dos séculos habitada por povos indígenas de diversas etnias, tendo a ocupação europeia começado já no século XVI, no início da colonização. Dessa forma, a região sempre foi vista como um lugar de fronteira 
entre a cidade do Rio de Janeiro e o interior do Brasil. Sem estradas e caminhos abertos para o interior e com a Serra do Mar ao fundo, a baixada permaneceu até o século XVIII como local de sesmarias e fazendas para a produção agrícola, como a Fazenda São Bento do Iguassú (SILVA, 2015, p. 235-237; SOUZA, 2006, p. 26-27).

No final do século XVII, com a descoberta do ouro, se tornou cada vez mais interessante a abertura de caminhos pelas matas, subindo as montanhas, para chegar às Minas. Nesse contexto, foram abertos os caminhos novos de Garcia Paes (1704) e suas variantes, que facilitavam o trânsito entre a cidade do Rio de Janeiro e as cidades mineiras. O Rio se tornaria a Capital da América Portuguesa em 1763, demonstrando a importância da região naquele século. Com a abertura dos caminhos novos e o Rio como Capital, a baixada ganha mais importância como região de passagem de mercadorias, do ouro e de outros metais e pedras preciosas. Assim, essa região de fronteira cresce em ocupação, nas margens dos caminhos criados (PERES, 1993, p. 23; OLIVEIRA, 2004, p. 7-12; ALVES, 2003, p. 33).

O contexto do século XIX impõe uma nova mudança à região. A instalação da Corte Portuguesa no Rio de Janeiro (1808), a emancipação política do Brasil (1822), a criação da Estrada do Comércio (1822) e das Estradas de Ferro Mauá (1854), d. Pedro II (1858) e Leopoldina (1886) aprofundariam o interesse pela região, seja para a produção de alimentos e para o tráfego entre a Capital do Brasil e o interior, seja para a ocupação de novas áreas e o combate a doenças e aos quilombolas daquela localidade. Seriam assim formadas novas Vilas e Freguesias. Essa nova estrutura de transportes possibilitou articulações entre o capital e o interior, criando uma interseção importante entre litoral e sertão, formando um lugar com relações sociais com pessoas de diversas origens e posições sociais nos caminhos (BEZERRA, 2004, p. 27).

Este território, fundamental para o novo país que acabava de surgir, permanecia infestado de doenças que poderiam chegar à Capital e de escravizados revoltados com sua condição, que poderiam atacar os comboios com as mercadorias que passavam. No ano de 1883 , se organizaria a primeira Comissão de Saneamento da Baixada, pelo Major Rangel de Vasconcellos. A partir de 1889, a concessão dos serviços passaria para o engenheiro civil João Teixeira Soares, com renovação, já no período republicano, em 1891. A noção de interdependência na questão das epidemias fazia com que houvesse grande 
preocupação com os males da baixada que poderiam chegar à Capital (GÓES, 1934, p. 1920).

No início do período republicano, com a nova estrutura política oligárquica descentralizada vigente, a situação política do Estado do Rio de Janeiro levava a novos desafios, dificultando a unidade de interesses dentro do Estado. De um lado, a elite política do Rio de Janeiro conservava um saudosismo de uma “idade de ouro", onde o Rio de Janeiro figurava como Corte e centro decisório do país. De outro, com a nova centralidade de Minas Gerais e São Paulo, a elite do Rio se fragmentou entre diversas forças políticas, sem a força centralizadora do Império (FERREIRA, 1989, 1994).

Nesse contexto, sob o governo de José Thomaz de Porciúncula, no Rio de Janeiro (1892-1894), foi criada a Comissão de Estudos e Saneamento da Baixada do Estado do Rio (1984-1902), com a chefia de João Teixeira Teles e depois de Marcelino Ramos da Silva (GÓES, 1934, p. 20). Em 1906, o engenheiro chefe do Serviço de Águas da Capital Federal, Sampaio Correia, solicitou ao diretor de Saúde Pública, Oswaldo Cruz, uma campanha contra a malária nos serviços de captação de águas dos rios Mantiqueira e Xerém. Mostrava-se mais uma vez a importância da baixada do Estado do Rio de Janeiro para a captação de águas e para a saúde pública da Capital. Os serviços contra a malária na baixada se iniciaram efetivamente tendo à frente Arthur Neiva e Carlos Chagas, em 1907, começando pelo acampamento dos trabalhadores e, mais tarde, nas regiões próximas. As taxas de mortalidade eram altas e, num terreno pantanoso e com muitas localidades alagadiças, a contaminação por malária chegava a 96 \% dos funcionários (STEPAN, 1976, p. 109; SILVA, 2006 p. 2-3). Em 1910, tendo na presidência da República o político fluminense Nilo Peçanha, se formou a Comissão Federal de saneamento e desobstrução dos rios que deságuam na baía de Guanabara (1910-1916) (ALVES, 2003, p. 56-59).

Nesses vários serviços sanitários, engenheiros e médicos de diversos órgãos do governo estadual e do governo federal testaram suas práticas e suas soluções para os problemas de saúde da baixada. E, para além disso, puderam fazer dessa região seus "sítios de pesquisas", observando os fenômenos no próprio local da campanha e levando amostras para os laboratórios e centros de pesquisas da capital. A partir dessa campanha, Oswaldo Cruz e outros médicos do Instituto Oswaldo Cruz (IOC) construíram novos programas para combate a malária, tiveram vitórias no combate à doença em outras 
partes do país, sobretudo em acampamentos para construção de ferrovias. Com isso, os médicos do IOC aumentaram seu prestígio e o alcance de suas propostas e de seus questionamentos sobre a organização dos serviços de saúde no Brasil (SILVA, 2006, p. 3).

A própria política local foi transformada pelas questões sanitárias. Em 1919, o decreto 1716, de 26 de novembro de 1919, ao mesmo tempo mandava executar os trabalhos de instalação da rede de esgoto da cidade de Nova Iguassú e criava a prefeitura, para a qual seria nomeado o médico sanitarista Mário Pinotti. O novo prefeito tinha acabado de se formar, em 1918, pela Faculdade de Medicina do Rio de Janeiro, e tinha assumido o comando do posto de saúde da Vila (NOVA IGUAÇU, 2003, p. 21-22). 0 médico Belisário Penna, em relatório do Serviço de Profilaxia Rural, enviado a Raul Veiga, presidente do Estado do Rio, enaltecia a nomeação, reafirmando a necessidade de aproximação entre a medicina e o Estado para enfrentar as demandas sociais, sanitárias e políticas daquela localidade (PENNA, 1920).

Contudo, essa decisão foi considerada uma "violenta ação contra a autonomia municipal" pelo presidente da câmara de vereadores, Ernesto França Soares. Naquele momento, a Câmara acumulava as funções de legislativo, executivo e o presidente da câmara atuava como intendente-geral. Através de um habeas corpus, Soares conseguiu retomar o poder municipal, se tornando prefeito (NOVA IGUAÇU, 2003, p. 21-22). Assim, apesar de não lograr êxito a nomeação de um médico para a prefeitura, ficava clara a tentativa de influência política estadual sobre a política da baixada e o prestígio dos médicos nos destinos dessa região.

As disputas entre as diversas esferas de poder, município, Estado e União pelo controle das políticas públicas, foi uma variável da disputa política no início do século XX. As tentativas de unidade e centralização dos serviços de saúde tinham como freio o federalismo presente na constituição de 1891. Desse modo, as diretrizes e a execução dos serviços públicos estavam em constante conflito de interesses (REIS, 1991, p. 49; HOCHMAN, 1998, p. 73-74). Não obstante, em todos os casos relatados, ficava patente a importância da baixada do estado do Rio de Janeiro como um sertão próximo à Capital, sob a influência política do Rio de Janeiro.

Assim, a baixada na Primeira República se constituiu como um campo de disputa política, como um sertão próximo doente que deveria ser curado e como um lugar de 
experimentação para médicos e engenheiros. Esses profissionais das áreas da saúde pública e da engenharia de saneamento pretendiam, curando os males da baixada, impedir que as doenças chegassem à Capital, conseguir recursos naturais importantes para o centro de poder brasileiro e adquirir experiência em campanhas de saúde e saneamento. Essa experiência poderia ser e foi replicada em outras partes do país, servindo as campanhas da baixada como modelos.

Como veremos, a construção da Escola Regional de Meriti seguiu esse mesmo padrão, pensando a baixada do estado do Rio de Janeiro como um local para a criação de uma experiência educacional que pudesse ser empreendida e divulgada como exemplo por diversos profissionais da Capital Federal: médicos, engenheiros, educadores, literatos e intelectuais em geral. Segundo Armanda Alberto,

\begin{abstract}
Sendo Meriti um distrito meio rural, meio operário, de população instável (os assentamentos no Livro de Generalidades provam-no de sobra), ora em caminho de sanear-se, portanto, de reter os habitantes, futuras alterações podem ser feitas [na estrutura da escola], segundo o tipo que venha a predominar em sua heterogênea população. A proximidade do Rio de Janeiro, se lhe traz inegáveis vantagens, traz-lhe, em troca, desvantagens sérias. (ALBERTO, 1997, p. 448-449)
\end{abstract}

A região estar próxima à Capital, ter ainda um ambiente considerado sertanejo, mas também com algumas características urbanas e estar às margens das ferrovias possibilitou a formação da instituição numa região de fronteira entre o litoral e o sertão. Existir ali um trabalho de saneamento e uma população heterogênea trazia vantagens para os intentos, mas também desafios. As principais vantagens eram ter o apoio dos sanitaristas e a proximidade da Capital. As principais desvantagens eram a constante mudança da população, os desafios de educar uma população que não conhecia princípios pedagógicos, a dificuldade de reter a população na localidade e de convencer os responsáveis de que seus filhos deveriam seguir um caminho de estudos e não de trabalho. Dessas experiências num sertão próximo constituíram-se carreiras, forjaram-se exemplos de possibilidades educativas e saneadoras dos sertões. 


\section{Movimentos educacionais e sanitários da Capital na década de 1910}

Na virada do século XIX para o século XX, as ideias de civilização e progresso chegavam ao Brasil, contudo, muitas vezes com uma visão negativista em relação ao país, ligada aos conceitos de Raça e de Natureza. A posição de Nina Rodrigues, por exemplo, estabelecia um contraste entre o litoral "reduto da civilização e dos grupos brancos" e o sertão “dominado por uma população mestiça, infantil, inculta, em estágio inferior da evolução social". Havia o desejo de fazer o Brasil avançar, alcançando o progresso e a modernidade, mas, ao mesmo tempo, a ideia de que isso não seria possível em razão das deficiências de sua população. Para essa visão, seria inútil tentar civilizar o sertão, pois a população seria racial e naturalmente inferior (LIMA, 1999, p. 60).

Em 1902, com a publicação de Os Sertões, Euclides da Cunha escreve um capítulo importante no debate sobre o contraste entre litoral e sertão, entre a ideia de civilização e a ideia de atraso. O isolamento do sertanejo seria descrito em detalhes, causando grande agitação na Capital Federal. Até então, havia muitos discursos sobre os sertões idealizados, mas a dureza da exposição euclidiana deu força a uma grande campanha de recuperação daquela brasilidade que se perdia. Esse movimento foi apoiado principalmente por setores descontentes com a conjuntura do início da República (ABREU, 1998, p. 94).

Críticos literários como José Veríssimo, Araripe Junior e Silvio Romero colaboraram para afirmar a autenticidade, científica e histórico-filosófica, artística e emotiva da obra de Euclides. A descrição do sertanejo como forte fisicamente e fraco moralmente ecoaria na intelectualidade do Rio de Janeiro, recriando nas próximas décadas a representação da dicotomia entre litoral e sertão (ABREU, 1998, p. 101-108). Um paradoxo se estabeleceria entre a visão do país real, que seriam os sertões, e do país legal, que seria o litoral; uma contradição entre uma "ordem ideal inadaptável” e uma "desordem empírica sufocante" (SÁ, 1998, p. 21). A tentativa de igualar o Brasil às nações europeias sofria de uma impossibilidade prática, que se afirmava cada vez mais no discurso da intelectualidade carioca.

A década de 1910 inaugurou uma nova forma de organização dos movimentos políticos no Brasil. Os intelectuais da Capital, envolvidos em projetos de modernização do 
Brasil, procuravam propor ações públicas para o salvamento da nação, através da educação e da saúde pública. O período da Primeira Guerra Mundial (1914-1918) incentivou o nacionalismo e comparações entre o Brasil e outros países e expandiu a estrutura de oportunidades políticas para a crítica ao contexto nacional. 0 descontentamento com a República oligárquica se somava ao contexto da guerra, colocando as bandeiras reformistas da defesa nacional, da educação, da saúde e da integração dos sertões em primeiro plano. A crença no progresso brasileiro, nesse contexto de nacionalismo militante, formaria um "programa de luta e a necessidade de organização de movimentos que deveriam atuar na salvação do país" (OLIVEIRA, 1990, p. 145).

O assassinato de Euclides da Cunha em 1909 reacenderia o clamor pela leitura do texto euclidiano como o Brasil real. No Ginásio Internato Nacional (atual Colégio Pedro II), Edgar Sussekind de Mendonça, Francisco Venâncio Filho e outros jovens estudantes fundaram o Grêmio Literário Euclides da Cunha editando, entre 1911 e 1939, uma revista sobre a vida e a obra do escritor. Importantes intelectuais da capital publicaram nesta revista, principalmente após o patrocínio de Alberto Rangel em 1914, amigo de Euclides e conhecido literato da época (ABREU, 1998, p. 300-303; VENÂNCIO FILHO, 2002, p. XIV$X V$ ). Venâncio Filho e Sussekind de Mendonça se reuniriam mais tarde com Armanda Álvaro Alberto na criação da Escola Regional de Meriti, dando o nome da biblioteca da escola de Euclides da Cunha (ALBERTO, 1921).

Em 21 de abril de 1915, no Club Militar, seria organizada a Liga Brasileira contra o Analfabetismo, tendo por principais ativistas Olavo Bilac, Reverendo Hugh Tucker, Maria Nascimento Reis Santos, entre outros. Embora no campo das ideias o programa da associação fosse muito simplista, com a indicação de instruções de leitura, aritmética, desenho geométrico e instrução cívica, a Liga expandiu o discurso em prol da educação brasileira (NOFUENTES, 2006, p. 3-4; MIGNOT, 2002, p. 142). O reverendo metodista Tucker tinha uma postura de maior preocupação com os pobres e com as questões sociais, sendo um dos fundadores do Instituto Central do Povo, criado em 1906, para atividades relacionadas à educação, saúde, higiene, trabalho, lazer e pregação religiosa para os pobres (CAMPANTE, 1985, p. 106-109). 
As atividades de Tucker, da Liga Brasileira contra o Analfabetismo e do Instituto Central do Povo cruzariam a trajetória de Armanda, principalmente depois de 1921. Nesse ano, a Liga passou a funcionar no prédio da Associação Cristã Feminina (ACF), da qual a intelectual participava. No jornal Triângulo Azul, da ACF, diversos artigos seriam divulgados no intuito de motivar as mulheres a combaterem o analfabetismo e empreenderem uma cruzada cívica pela salvação do país. Na ACF, com a presença de mulheres cristãs estrangeiras, a jovem Armanda teria contato também com novos princípios educacionais que surgiam nos EUA e na Europa. Nos anos seguintes, publicaria artigos no jornal e se tornaria uma personagem importante e admirada neste contexto, se tornando vice-presidente da Liga em 1923 (MIGNOT, 2010).

No mesmo período de fortalecimento dos intelectuais euclidianos e da Liga contra o Analfabetismo, o movimento sanitarista se destacava como uma importante voz em prol do saneamento do Brasil e de uma grande campanha para levar educação e saúde ao Sertão. Entre 1908 e 1922, o Instituto Oswaldo Cruz (IOC) empreendeu uma série de expedições científicas pelo interior do Brasil - em acordos com companhias ferroviárias, órgãos federais e governos estaduais - para estudos médico-científicos, trabalhos profiláticos e pesquisas sobre a flora, a fauna e a geografia médica nos sertões (LIMA, 1999, p. 79-89).

A partir do início da década de 1910, o IOC se tornava um importante centro de pesquisas médicas, ganhando cada vez mais relevância para a intelectualidade brasileira. Em outubro de 1916, o presidente da Academia Nacional de Medicina e professor da Faculdade de Medicina do Rio de Janeiro, Miguel Pereira, pronunciou um discurso no qual afirmava que "O Brasil é ainda um imenso hospital”. Embasado no relatório de viagem de Belisário Penna e Arthur Neiva, produzido em expedições a estados do Nordeste, Norte e Centro-oeste, o médico diagnosticava a doença como um mal em todo o país. O relatório Penna-Neiva tinha sido publicado nos jornais, causando grande polêmica na imprensa, nos círculos médicos, intelectuais e políticos (HOCHMAN, 1998 p. 63-66; LIMA, 1999, p. 87).

Até então, não existia um outro diagnóstico produzido por médicos de uma importante instituição científica nacional que mostrasse com tamanha duração e extensão territorial as condições de vida e de trabalho da população local. Entre 
novembro de 1916 e janeiro de 1917, Penna publicou artigos no jornal Correio da Manhã sobre as condições de salubridade do país e sobre planos de saneamento nacional, nos quais conclamava a todos para uma campanha pelo saneamento do Brasil. Em alguns desses artigos, Penna citava explicitamente regiões da baixada do Estado do Rio de Janeiro, procurando demonstrar como a doença, a miséria, a falta de educação e o esquecimento dos poderes públicos devastavam aquelas localidades (PENNA, 1918).

Em fevereiro de 1917, com a morte de Oswaldo Cruz, grande inspirador do Instituto que leva seu nome, cresceu o sentimento de que seria necessária uma grande campanha pelo saneamento do Brasil. Exatamente um ano depois, foi criada a Liga PróSaneamento do Brasil, colocando o combate às endemias rurais como foco principal de suas atividades (BRITTO, 1995). A criação da Liga Pró-Saneamento enfatizou a recuperação e integração do país e do sertanejo, trazendo novamente à tona o debate dos euclidianos, dessa vez no âmbito da saúde. Com uma postura contra a condenação racial e climática do povo brasileiro, o movimento atraiu e aliviou boa parte da intelectualidade da época. Tornou-se marcante o desabafo de Monteiro Lobato, em Problema Vital (1918), no qual afirmava que “O Jeca não é assim: está assim”. Ou seja, sanear e educar o sertanejo seria a forma de curá-lo, de enriquecê-lo e de moralizá-lo (LIMA; HOCHMAN, 1996).

A partir de setembro de 1918, uma grande epidemia de Influenza, conhecida como “gripe espanhola", tomaria o país, matando milhares de pessoas. O crescimento do número de mortos e contágios serviu como um catalisador de políticas públicas de saúde, com efeitos permanentes. A noção de que efeitos negativos das doenças poderiam chegar a todos e de que haveria uma interdependência social entre os grupos sociais e entre as localidades se fortaleceu. Se, antes da epidemia, havia muitos movimentos políticos e pouca ação governamental, depois da Influenza, foram organizados diversos postos de saúde na Capital Federal e na baixada do Estado do Rio de Janeiro e, em 1920, foi criado o Departamento Nacional de Saúde Pública. O DNSP se tornaria na década de 1920 o órgão de centralização das políticas públicas de saúde e, após 1930, se tornaria um dos departamentos do novo ministério da educação e saúde do governo Vargas (HOCHMAN, 1998). 
Essa seria uma vitória importante do movimento sanitarista e daria força ao seu principal divulgador, Belisário Penna. O médico apoiaria e faria conferências na Escola Regional de Meriti, além de levar médicos para apoiarem a escola. A presença de Penna na Escola seria tão marcante que o logradouro da Escola, em Meriti, passaria a se chamar Rua Belisário Penna. Segundo o médico, a solução para o problema vital brasileiro - que era a falta de saneamento, com conceitos de higiene, saúde, educação sanitária e puericultura - viria de iniciativas como a de Armanda Álvaro Alberto e da Escola Regional de Meriti (PENNA, 1968, p. 76).

A união entre os partidários do movimento euclidiano, do movimento contra o analfabetismo, do movimento sanitarista e dos movimentos femininos e de outros intelectuais na década de 1910 levaria a criação da Escola Regional de Meriti, sob a direção de Armanda Álvaro Alberto. Longe de ser uma iniciativa individual, era um empreendimento que tinha uma direção clara na figura de Armanda, mas tinha também o apoio de diversos círculos intelectuais da Capital federal. Com estes apoios, Armanda Álvaro Alberto, Edgar Sussekind de Mendonça e Francisco Venâncio Filho puderam idealizar e concretizar os planos de construção de uma escola proletária e regional em Meriti.

\section{A Escola Regional de Meriti como experiência educacional e sanitária}

Como vimos, a baixada do Estado do Rio de Janeiro era um território conhecido por ser um sertão próximo à Capital Federal, que tinha diversas conexões com a política, a saúde e a organização da sociedade carioca. Essas conexões se aprofundaram nos tempos da Primeira República, através de ações de saúde e saneamento na região, de tentativas do governo federal e estadual de influir na política local e de obras públicas vinculadas aos interesses do Rio de Janeiro. Os movimentos políticos e sociais da década de 1910 colaboraram para que a intelectualidade carioca desejasse ir até os sertões, no intuito de salvar o país através da educação e da saúde.

Mas onde estava Armanda Álvaro Alberto neste contexto?

A educadora, que se tornaria diretora da Escola Regional de Meriti, passou a maior parte da sua infância acompanhando seu pai, o médico Álvaro Alberto Silva, e sua família 
em viagens de estudos no exterior e em seu trabalho como médico no Brasil. O dr. Álvaro Alberto foi redator de revistas médico-científicas brasileiras no século XIX, viajou para estudar em países como Bélgica e França, estudou e produziu sobre febre amarela, química, história natural, explosivos e pirotecnia. A educação de Armanda foi feita por preceptores particulares e por sua própria mãe, Maria Teixeira da Motta e Silva. É provável que a jovem Armanda conhecesse línguas estrangeiras, através de seus pais e de suas viagens pela Europa, facilitando a leitura de escritores e educadores europeus e estadunidenses (MIGNOT, 2002, p. 79-80; MIGNOT, 2010, p. 22-23).

Álvaro Alberto Silva faleceu em 1908. Para seus filhos, o médico deixava conhecimentos e uma rede de relações importantes com a intelectualidade da Capital. Álvaro Alberto da Motta e Silva, na época com 18 anos, já provavelmente colaborava com o pai nos seus empreendimentos e estudos. Em 1920, criou a fábrica de explosivos Rupturita, junto com seu amigo Francisco Venâncio Filho, na vila de Meriti, sem, contudo, registrá-la, pois era impedido legalmente por ser da Marinha. (MIGNOT, 2010, p. 22-24) Armanda Álvaro Alberto um pouco após a morte do pai passou a estudar no Colégio Jacobina, que buscava adotar os princípios das escolas ativas no Brasil. No Jacobina, lecionava Heitor Lyra da Silva, que buscava divulgar os métodos das escolas novas europeias no Brasil e seria um dos grandes entusiastas da ERM (LACOMBE, 1962; LEAL, 2002).

A criação da Escola na vila de Meriti acontece exatamente no encontro entre aquela localidade e a trajetória dos dois irmãos, informada pelos ideais dos movimentos educacionais e sanitários daquela conjuntura. Ao visitar a fábrica Rupturita, em 1921, Armanda considerou ser aquele um excelente lugar para uma escola proletária e regional (MIGNOT, 2010, p. 24). Havia ali um ambiente sertanejo, com trabalhadores em lugar meio-rural meio urbano, uma população com muitos analfabetos e com poucas ou nenhuma posse ou riqueza, em uma região considerada insalubre e sem saneamento. Nos anos seguintes, a trajetória de Armanda Álvaro Alberto ficou marcada pela construção da Escola Regional de Meriti e pelas repercussões desta iniciativa educacional e sanitária no cenário nacional.

No momento em que decidem fundar uma Escola, Armanda Álvaro Alberto e Edgar Sussekind de Mendonça e Francisco Venâncio Filho tinham um grande círculo de 
amizades nos movimentos femininos, nas organizações médicas, entre os euclidianistas, nos movimentos protestantes, no Colégio Jacobina, nas diversas associações e ligas de salvação nacional. Com Edgar Sussekind, Armanda Alberto tinha um flirt e mais tarde, em 1928, os dois se casariam. Já Francisco Venâncio, como vimos, era amigo e sócio de seu irmão, Álvaro Alberto da Motta e Silva. Ao longo das décadas seguintes, os três formariam a direção da Escola Regional de Meriti, conseguindo cada vez mais apoiadores (MIGNOT, 2010, p. 24-26).

No primeiro ano já contavam com o apoio de Edgar Roquette Pinto, do Museu Nacional, Pacheco Leão, do Jardim Botânico, Heitor Lyra da Silva, da Escola de Belas Artes e do Colégio Jacobina, e de muitos outros intelectuais da Capital. No segundo ano de funcionamento, com a criação da Caixa Escolar Dr. Álvaro Alberto, as despesas passaram a ser custeadas com a adesão de dezenas de sócios contribuintes. Com isso, a iniciativa ganhava força e meios de se manter financeiramente, com o apoio de diversas famílias da elite carioca (ALBERTO, 1921; ALBERTO, 1922).

Os relatórios anuais da primeira década da Escola Regional de Meriti ${ }^{1}$ procuravam descrever e analisar as estruturas, construções, iniciativas, os objetivos, as realizações, fracassos e os desafios enfrentados pela instituição educacional. Além de informações sobre a escola, os documentos trazem descrições sobre a Vila de Meriti, sua população, a vida das famílias da região e sobre questões de saúde, epidemias e estado sanitário da localidade. Nessas fontes, a história da localidade, a história da escola nova no Brasil e a história da saúde se cruzam na trajetória da ERM e é possível compreender as múltiplas possibilidades de visões sobre os acontecimentos relacionados.

Sobre os relatórios, o escritor Carlos Drummond de Andrade publicou uma crônica chamada "Uma escola viva", em 1945, momento em que era chefe de gabinete do Ministério da Educação de Gustavo Capanema. (ARINOS FILHO, 2003, p. 143). Armanda enviava seus relatórios para sócios, professores, responsáveis por estudantes, amigos intelectuais, além de associações e repartições públicas que considerava convenientes. Segundo Drummond de Andrade (1968, p. 133-134), o relatório anual da Escola Regional de Meriti não seria “coisa enfadonha”, era muito bem escrito e através dele era possível

\footnotetext{
1 Nas pesquisas que originaram este artigo, analisei os Relatórios Anuais da Escola Proletária (depois Regional) de Meriti dos anos de 1921, 1922, 1923, 1926, 1928 e 1930, que estão na Coleção da Escola Regional de Meriti, sob guarda do Instituto Histórico da Câmara Municipal de Duque de Caxias.
} 
que os responsáveis pelos estudantes e a sociedade de forma geral tomasse conhecimento e se interessasse pela vida escolar. No texto o escritor informava que "todos os anos, o trabalho escolar é passado em revista e miudamente analisado em seus êxitos e falhas" (ANDRADE, 1968, p. 134).

As análises empreendidas por Ana Chrystina Mignot (2002) e por Julio Paixão Santos (2008) demonstram como, ao descrever também os percalços, Armanda Álvaro Alberto abre espaço nas suas memórias escolares para a percepção dos limites do educandário. Deste modo, analisar os relatórios da ERM é um bom caminho para compreender a construção da experiência escolar desta instituição e perceber como ela era ao mesmo tempo inovadora e fruto do seu próprio tempo.

A Escola Regional de Meriti tinha na sua infraestrutura o Lar-Escola (prédio escolar), a Biblioteca Euclides da Cunha e o Museu Regional de Meriti. Considerava a Saúde, a Alegria, o Trabalho e a Solidariedade como seus princípios norteadores gerais. Pretendia ser uma escola sem notas, prêmios e castigos (ALBERTO, 1997, p. 447). Não obstante, nos primeiros anos, Armanda acabou tendo que agir contrariamente aos princípios declarados, dando provas aos seus alunos para selecionar as crianças para as turmas adiantadas ou atrasadas. Além disso, em concursos como o “Janelas Floridas”, em que as meninas enfeitavam as casas da vila de Meriti, ou de "Utilidades", no qual os meninos produziam trabalhos de carpintaria, haviam prêmios (ALBERTO, 1921, 1922, 1923).

Explicando as razões para a existência de prêmios nos concursos, Armanda escreveu para seus sócios:

Uma explicação. A distribuição de prêmios nestes dois concursos não é uma quebra de normas adotadas. É que destinados a trazer uma parcela de beleza à vida, sem encantos deste povoado, são eles manifestações de atividade fora da Escola. De mais a mais, é preciso contentar as famílias... no caso, diretamente interessadas. (ALBERTO, 1923, p. 9)

Assim, além do encorajamento ao trabalho e à ornamentação da vila, a diretora considerava necessário atrair as famílias, para que estas se aproximassem da escola e entendessem os métodos e as iniciativas da instituição. Vale ainda ressaltar que, fruto do seu tempo, as iniciativas de concursos da escola ainda se dividiam entre tarefas de 
meninos e de meninas, mesmo que Armanda se tornasse conhecida por sua luta em movimentos femininos.

Buscar o apoio familiar era fundamental para tentar evitar as constantes faltas às aulas e evasão escolar, que existiu na ERM neste período inicial. No que tange as relações entre educação e saúde, médicos do Serviço de Profilaxia Rural e profissionais do Museu Nacional faziam atendimentos médicos e fichas de saúde das crianças, tentando evitar doenças que atingiam a baixada neste momento e eram razões de faltas (ALBERTO, 1921, p. 5). A importância da Escola Regional de Meriti foi tão grande na história da saúde pública na vila que o posto de saúde inaugurado em 1919, ao deixar de existir, em 1922, passou suas funções para a escola, que além de cuidar da saúde dos estudantes passou a tratar das doenças das famílias e outros moradores (ALBERTO, 1922, p. 3).

A evasão escolar também era constante naqueles tempos da escola. No ano de 1921, 25 crianças saíram da escola. A diretora Armanda Alberto solicitava que os responsáveis comunicassem os motivos da retirada dos estudantes. As razões alegadas eram: 5 estudantes para trabalhar, 12 pela mudança de residência, 2 pois "moravam distante demais" e 6 por terem ido estudar em outra escola (ALBERTO, 1921, p. 5-6). À fraca assiduidade e às evasões se somava o problema da oscilação do número de matrículas. Segundo Armanda, três fatores foram relevantes para a melhoria do quadro: a ocupação do cargo de médico, o ensino de trabalhos manuais e a eliminação dos "vadios" (ALBERTO, 1922).

A questão da expulsão dos “vadios", "menos adaptáveis" ou “inadaptáveis” à escola mostra como, na experiência da Escola Regional de Meriti, a cultura de moralização, da normalização e controle da Primeira República brasileira estava presente. Demonstrava-se uma inabilidade da Escola em cumprir seus objetivos de educar os sertanejos e uma forma de reproduzir no sertão a organização de uma elite. No discurso enviado para a Primeira Conferência Nacional de Educação, em 1927, Armanda Alberto escreveu:

Para a formação das turmas vigora o grande desenvolvimento intelectual, podendo o aluno passar de uma para outra em qualquer época, porque não se fazem exames nem se corre ou estaciona a espera dos colegas. Os anormais, os inadaptáveis ao regime da Escola e os que faltam sem justificativas são eliminados. (ALBERTO, 1997, p. 449) 
Assim, haviam expulsões por não conseguir acompanhar os conteúdos pedagógicos da escola, por praticar roubos ou furtos, por vadiagem dos estudantes. Este aspecto tem profunda relação com a ideia de que o sertanejo era moralmente fraco, presente no texto euclidiano e no repertório da intelectualidade da capital federal. Além disso, a partir das análises de Michel Foucault (1979), acerca do biopoder, da microfísica do poder e do controle sobre os corpos, podemos perceber como a educação e a saúde foram utilizadas como ferramentas de controle, de diferenciação entre o normal e o anormal e de moralização das atividades que não estavam num padrão considerado civilizado.

Nesse sentido, o Círculo de Mães, a partir de 1925, buscava ao mesmo tempo aproximar as responsáveis pelas crianças da escola e orientar a forma como a educação deveria acontecer em casa (LOURENÇO FILHO, 2002, p. 268; MIGNOT, 2002, p. 195-197). Diversas outras iniciativas da ERM, como palestras de médicos e outros intelectuais, sessões de cinema, atividades de profilaxia sanitária de crianças e famílias buscavam criar um ambiente no qual as crianças, seus responsáveis e a sociedade da vila de Meriti como um todo pudessem aprender os melhores hábitos de saúde, higiene e educação. Eram uma das formas de criar um ambiente saudável para a divulgação científica, educacional e de higiene e saúde, enfim, dos ideais de civilização pelo interior (SANTOS, 2008, p. 163164).

Em 1925, se iniciou um curso público de higiene rural, promovido pela escola e ministrado pelos médicos Belisário Penna e Savino Gasparini, que durou até o ano seguinte (MIGNOT, 2002, p. 194; ALBERTO, 1928, p. 9). Em aula ministrada no dia 12 de julho de 1925, no Cinema de Meriti, Penna descreveria com clareza sua concepção de escola e da importância de professoras e crianças na formação de uma consciência sanitária nacional. A fotografia 01, feita neste dia, está tanto no arquivo de Armanda Álvaro Alberto, quanto no Arquivo de Belisário Penna, denotando que o evento marcaria o encontro dos dois e as relações entre os movimentos sanitarista e educacional. De acordo com Belisário Penna,

Essa escola é um empreendimento auspicioso, que exprime melhor do que palavras os sentimentos, altruísticos, patrióticos e humanitários da sua fundadora e dos seus dignos e abnegados colaboradores. É um 
produto de iniciativa particular, digno de imitação e do incentivo e colaboração, material, moral e intelectual de todos aqueles que desejam sinceramente contribuir para a evolução do organismo brasileiro, dentro das leis imutáveis da Biologia humana, dos preceitos científicos da Higiene, da Eugenia e da Educação intelectual, moral, e cívica, de que resultam a saúde física e mental. (PENNA, 1925, p. 1)

\section{FOTOGRAFIA 01 - Visita à Escola na inauguração do curso público de higiene rural}

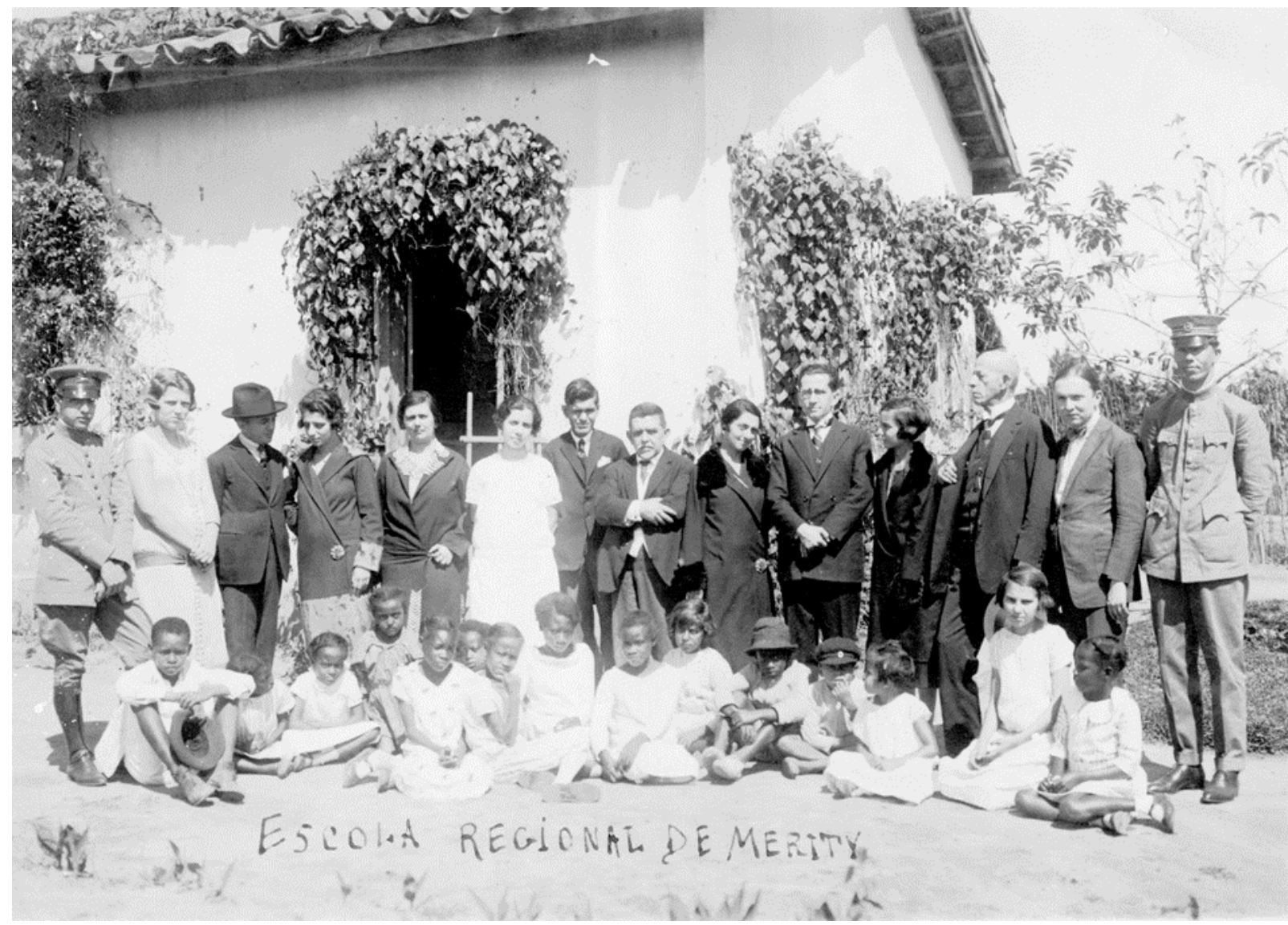

Legenda: Belisário Penna (no centro da imagem) é fotografado com a Francisco Venâncio Filho (a sua direita) e Armanda Álvaro Alberto (a sua esquerda), Savino Gasparini (a esquerda de Armanda), Edgar Sussekind de Mendonça (penúltimo à direita), outras autoridades locais e os estudantes da ERM, antes da inauguração do curso de higiene rural. Esta foto se encontra tanto no Arquivo Belisário Penna quanto na Coleção da Escola Regional de Merity.

Fonte: Fundo Belisário Penna. BP(F-VPP)7-66. Casa de Oswaldo Cruz/FIOCRUZ. Rio de Janeiro, 1925.

Não obstante, havia divergências sobre o papel da criança e dos métodos pedagógicos entre a posição de Penna e a perspectiva de Armanda Alberto. Se para Penna, "como o povo, a criança é imitadora, porém mais do que ele, é assimiladora e fixadora" (PENNA, 1925, p. 4), para Armanda, deveria-se utilizar quaisquer métodos 
educacionais, "desde que se baseiem na liberdade, que consente a plena expansão da individualidade, e no trabalho, que leva a criança a observar, a experimentar, a descobrir e a fazer por si" (ALBERTO, 1997, p. 451). Assim, Penna demonstrava uma visão de educação mais conservadora e controladora da criança, pensando a criança como imitadora e assimiladora, enquanto Armanda desejava uma educação mais livre e com expansão da individualidade.

Apesar das divergências de posições intelectuais, diversos intelectuais da capital federal participaram direta ou indiretamente das atividades da Escola, como Belisário Penna, Savino Gasparini, Renato Kehl, Edgar Roquette Pinto, Antonio Pacheco Leão, Julia Lopez de Almeida, entre outros. Aos poucos, com a distribuição dos relatórios anuais da instituição, com os diálogos no Rio sobre o que se fazia na escola e com palestras que buscavam divulgar a iniciativa, a Escola Regional de Meriti passou a ser cada vez mais conhecida. Isto gerava muitos elogios, mas também algumas críticas relacionadas às concepções do educandário.

De forma geral, a Escola passou a ser nos discursos da capital um exemplo de instituição que deu certo no sertão e poderia ser replicada em diversas partes do Brasil. Na Associação Brasileira de Educação, criada em 1924, nas Conferências Nacionais de Educação que aconteceriam a partir 1927, e em publicações de Lourenço Filho, como sua Introdução ao Estudo da Educação Nova, de 1930, a iniciativa era louvada com muitos elogios. Assim, de uma experiência educacional no sertão, a ERM passou a se constituir como um exemplo de possibilidade de educar e sanear os sertões e os sertanejos.

\section{Modernização e Regionalismo na perspectiva da Escola Regional de Meriti}

O ideal de civilização e modernização conservadora da elite carioca pressupunha a ida para os sertões, para convencer os sertanejos de que as práticas higiênicas, sanitárias e educacionais eram as mais eficazes para desenvolver o Brasil. Para tanto, se recorria tanto às tentativas de influenciar os poderes públicos, quanto às iniciativas particulares. Contudo, para Penna e outros intelectuais da década de 1920, eram claras as demonstrações de que os governos tinham fracassado nas suas funções de civilizar. 
Mesmo com a criação do Postos de Profilaxia Rural, entre 1918 e 1919, e do Departamento Nacional de Saúde Pública, em 1920, os médicos que trabalhavam nestes serviços públicos tinha, naqueles anos, a percepção de que o setor privado seria o local para realizar seus ideais de pátria. E isto estava marcado na fala de Belisário Penna, ao afirmar que: A Escola Regional de Meriti fundada há quatro anos pela jovem e exímia
educadora, Da. Armanda Álvaro Alberto, e o Museu de Higiene Popular,
inaugurado há poucos dias em Niterói, feito e organizado pelo provecto
clínico e higienista Dr. François Norbert, são duas valiosas instituições de
educação popular, que revelam a eficiência da iniciativa particular,
quando orientada por inteligências esclarecidas, almas idealistas e
corações sensíveis, que se não limitam a sonhar e sentir, mas realizam,
com patriótica abnegação, os ideais, e gozam o prazer sem par da sua
realização e dos benefícios que espalham, através de penosos trabalhos
de luta incessante e diária, para convencer os próprios beneficiados.
(PENNA, 1968, p. 80)

De igual modo, para Armanda Álvaro Alberto, "sem a iniciativa particular, o Brasil não resolverá tão cedo o problema da educação do seu povo, simplesmente porque faltam à União e aos estados os recursos financeiros suficientes" (ALBERTO, 1997, p. 451). Neste sentido, para Armanda,

A Escola Regional de Meriti tem por máxima aspiração ser reproduzida em todo o país. Que os fazendeiros, os industriais, os capitalistas fundem escolas para os filhos de seus colonos sitiantes, operários, empregados... Peçam aos poderes públicos ou aos centros de educação, como a Associação Brasileira de Educação, os programas, mesmo as professoras, no que não haverá prejuízo para o governo. E aqueles que só dispõem da boa vontade fundem associações como a nossa [ABE], que o ocupar-se da criança ainda é a mais humana das funções da nossa espécie. (ALBERTO, 1997, p. 451)

Com esta perspectiva, educadores e médicos propunham que os problemas educacionais do Brasil fossem solucionados pela união entre os poderes públicos e as iniciativas particulares no sentido de educar os operários, empregados, colonos, sertanejos. Para Edgar Sussekind de Mendonça, era função das escolas regionais resolver os problemas locais da população, principalmente da manutenção dos alunos na escola, do incentivo e proteção à indústria local e da divulgação da higiene da beleza e da educação (MENDONÇA, 1968, p. 18-19). Além disso, Mendonça afirmava que 
se tomamos para campo de experiência a pequena povoação fluminense de Meriti, não foi para constituir um exemplo de perfeição, ou mesmo apurada qualidade, mas foi para constituirmos um exemplo de possibilidade de realização, que mais valesse porque nos cercamos, justamente, das menos vantajosas das condições locais. Justamente por causa das péssimas condições peculiares a uma povoação desorganizada parasitando um grande centro, onde a civilização, por mal compreendida, só mostra o reverso da medalha - região nem tipicamente urbana, nem tipicamente rural; justamente por isso é que podemos afirmar que o pouco que aí venceu poderá vencer em qualquer parte do Brasil. Somos um pequeno grupo de professores cariocas, atentos dia a dia à vontade de quem nos reuniu; contamos apenas com os recursos materiais da Fundação Álvaro Alberto de exclusiva iniciativa particular. (MENDONÇA, 1968, p. 22)

Nesta publicação, um dos criadores da ERM afirmava com todas as letras a dimensão da baixada como região de fronteira meio rural meio urbana, como campo de experiência. Além disso, ressaltava a divulgação da escola como um exemplo de possibilidade de realização que deveria ser replicada por todo o país, nas condições mais desfavoráveis possíveis. Outro aspecto que vale ser ressaltado é que o regionalismo do ensino, para Mendonça, deveria ser espalhado por todas as partes do Brasil.

Mas o que seria o regionalismo na educação, deste ponto de vista?

Para os criadores da Escola Regional de Meriti, o regionalismo deveria prever a adequação da escola às demandas locais, procurando incentivar a produção na própria localidade, a partir das potencialidades de cada ambiente. Logo, não se esperava que os sertanejos fossem educados para desejar sair do sertão e ir para a Capital. Pelo contrário, a perspectiva era de que fossem educados para o estudo, a partir do seu meio, produzindo ali seu sustento, através da pecuária, da agricultura, dos trabalhos manuais, da jardinagem, da carpintaria, entre outras atividades. Assim, o trabalho era visto como um valor na Escola e uma forma de aperfeiçoar as crianças em profissões.

De acordo com Armanda, tão problemática quanto à saída de estudantes da escola para trabalhar era a saída de estudantes para estudar na Cidade, trilhando o caminho do bacharelado (ALBERTO, 1926, p. 6). A procura do bacharelato na Capital era equivocada para estes intelectuais que lutavam contra o ensino enciclopédico, contra uma Razão Pomposa. Como explica Dominichi Sá, a crítica à ideia de uma cultura da memória, de 
reter o máximo de informações, se fazia sentir nas primeiras décadas do século XX, no

Brasil. Essa geração pertencia à cultura da inteligência, que unia uma perspectiva antibacharelesca com uma valorização do sertão (SÁ, 2006).

Deste modo, havia um desejo de ensinar o sertanejo a valorizar o sertão, o que ele teria de bom, permanecendo no interior e vivendo de acordo com as formas modernas e civilizadas de ser, agir, produzir e organizar a sociedade. De acordo com Mendonça, na escola, com o tempo, os sertanejos valorizariam a si próprios. A população de Meriti aprenderia sobre as riquezas do Brasil, percebendo as belezas e potencialidades de cada uma das grandes regiões brasileira. Para este educador, não seria compreensível uma nacionalidade sem "as linhas gerais e características de cada região, diretamente ensinadas para ser sinceramente compreendidas" (MENDONÇA, 1968, p. 22).

Contrário a esta posição, o intelectual católico Alceu Amoroso Lima, de codinome Tristão de Athayde afirmava, em “O Jornal”, no ano de 1925:

\begin{abstract}
Condição Primordial de Eficácia
E o que de excelente escreveram os senhores Francisco Venâncio Filho e Edgar Sussekind de Mendonça, sobre essa tentativa muito interessante e bem orientada da Escola Regional de Meriti. A não ser aquele absurdo de "região dando lição de moral" para justificar o emprego da moral prática, de moral leiga, em vez de moral religiosa, por um qualquer preconceito de anti-clericalismo ou de liberalismo muito pouco realista, muito pouco "regionalista".

Aliás, é necessário, por sua vez, que a necessidade de adaptação da escola às variedades de meios e de gentes, condição primordial de sua eficácia não degenere justamente no que há de acanhado e de perigoso no regionalismo. Defendendo-se da objeção, escreve o sr. Edgar Sussekind de Mendonça que isso "é uma questão de confiança na unidade brasileira". Infelizmente, nesse assunto não há questões de confiança e sim de desconfiança. (ATHAYDE, 1968, p. 31)
\end{abstract}

Mostrava-se uma contrariedade e uma crítica ácida a concepção de regionalismo e de região da Escola Regional de Meriti. Se para os criadores da Escola, a região era um local de potencialidades e o sertanejo deveria valorizar o seu lugar, para Amoroso Lima, o regionalismo tal qual defendido pela escola era absurdo pois quebraria o sentido de unidade nacional e criaria uma percepção de que a região, o sertão, seria melhor do que o litoral e sua civilização. Segundo Ana Magaldi, a Primeira República também foi um 
período de disputas entre a Igreja Católica e intelectuais católicos - que defendiam uma nação católica e a unidade nacional, contra intelectuais que buscavam ver o Brasil como uma diversidade de regiões, valorizando os regionalismos (MAGALDI, 2007, p. 100).

Em 1931, seria realizado um congresso da Associação Brasileira de Educação, tendo como tema geral a "Escola Regional". Neste evento, as propostas do regionalismo no ensino foram defendidas (CARVALHO, 1998, p. 161). Para Belisário Penna, defensor da perspectiva do regionalismo, a escola, o saneamento e a pequena propriedade eram elementos que poderiam modificar radicalmente o meio social brasileiro. $O$ médico propunha a distribuição de terras para os homens da terra, os camponeses, afirmando que $90 \%$ das famílias brasileiras não possuíam um "lar próprio, nem qualquer trecho de terras". Essas medidas possibilitariam a "prática de virtudes higiênicas do asseio, da temperança, da laboriosidade e do conveniente aproveitamento e uso dos elementos naturais e essenciais à vida - a terra, a água, o ar e o sol" (PENNA, 1931 apud CARVALHO, 1998, p. 163).

Por sua vez o engenheiro Barbosa de Oliveira afirmava que para cada tipo de região brasileira deveria existir uma forma regional própria de escola, valorizando o trabalho e as aptidões regionais. Em vários discursos, a Escola Regional de Meriti apareceria como uma afirmação de possibilidade da perspectiva regional na educação, contra a uniformização do ensino em todo o país. (OLIVEIRA, 1968).

Como procurei demonstrar, a ideia de modernização e de civilização deste grupo de intelectuais da capital federal não tinha como pressuposto a uniformização da nação a partir da capital. Era, pelo contrário, uma tentativa de resolver os males do sertão e possibilitar que os sertanejos permanecessem nas suas regiões, tendo estudos e saúde para empreender. A Escola Regional de Meriti era fundamental neste projeto pois se apresentava como uma experiência que deu certo como escola regional e que poderia ser um exemplo de possibilidade de aplicação da ideia em todo o país. Armanda Álvaro Alberto, Edgar Sussekind de Mendonça e Francisco Venâncio Filho foram os principais atores desta construção. Contudo, a experiência educacional e sanitária do educandário, em sua dimensão de modernização e regionalismo, foi um trabalho de muitas mãos, que teve apoio direto e indireto de diversos intelectuais da capital federal alinhados com os princípios de valorização dos sertões. 


\section{Considerações finais}

Passados 100 anos de inauguração da Escola Proletária, depois Regional, de Meriti, muitos desafios educacionais ainda se colocam para o Brasil. Olhar para o passado desta instituição educacional pode nos ajudar a entender como as relações entre a escola e a família, entre os educadores e a sociedade no seu entorno e entre professores e estudantes são fundamentais para um projeto educacional de qualidade.

A ERM muito antes do presente já colocava as questões da alimentação escolar, da conexão entre os estudantes, a natureza e a sociedade e da importância da família na educação em primeiro plano. Os trabalhos de estudos da natureza, através dos quais se recolhiam objetos para serem catalogados no Museu Nacional e no Jardim Botânico do Rio de Janeiro, podem ser exemplos de como as atividades pedagógicas devem propiciar atividades de pesquisa, relacionadas ao conhecimento científico e ao mesmo tempo ao interesse ativo da criança.

Deste modo, analisar a trajetória da Escola Regional de Meriti nos seus primeiros anos torna-se um alargamento do espaço de experiência histórica para que pensemos, hoje, em alternativas educacionais para um mundo atingido por uma pandemia e por outras questões políticas, sociais e culturais. Construir novos horizontes de expectativas educacionais é uma tarefa do presente. E o estudo da História da educação brasileira pode contribuir para a formulação de propostas educacionais relevantes.

\section{Referências}

ABREU, Regina. O enigma de Os Sertões. Rio de Janeiro: Funarte: Rocco, 1998.

ALBERTO, Armanda Álvaro. A Escola Regional de Meriti: uma tentativa de escola moderna. (Tese n. 79). In.: COSTA, Maria J. F. Ferreira da; SHENA, Denilson R.; SCHIMIDT, Maria. (orgs.). CONFERÊNCIA NACIONAL DE EDUCAÇÃO, 1., 1927, Curitiba. [Anais]. Brasília: INEP, 1997. 
ALBERTO, Armanda Álvaro. A Escola Proletária de Merity no ano de 1921. Rio de Janeiro: [s. n.], 1921. Datilografado.

ALBERTO, Armanda Álvaro. A Escola Proletária de Merity no ano de 1922. Rio de Janeiro: [s. n.], 1922. Datilografado.

ALBERTO, Armanda Álvaro. A Escola Proletária de Merity no ano de 1923. Rio de Janeiro: [s. n.], 1923. Datilografado.

ALBERTO, Armanda Álvaro. A Escola Regional de Merity no ano de 1926. Rio de Janeiro: [s.n.], 1926. Datilografado.

ALBERTO, Armanda Álvaro. A Escola Regional de Merity no ano de 1928. Rio de Janeiro: [s.n.], 1928. Datilografado.

ALVES, José Cláudio. Dos barões ao extermínio: uma história da violência na Baixada Fluminense. Duque de Caxias: APPH-CLIO, 2003.

ANDRADE, Carlos Drummond de. Uma escola viva. In: ALBERTO, Armanda Álvaro. A Escola Regional de Meriti (Documentário) 1921- 1964. Rio de Janeiro: MEC-INEP-CBPE, 1968. p. 131-135.

ARINOS FILHO, Afonso. Itinerário poético de Drummond. Revista Brasileira, Rio de Janeiro, fase VII, ano IX, n. 36, p. 129-156, jul./set. 2003.

ATHAYDE, Tristão de. (Alceu Amoroso Lima). Condição Primordial de Eficácia. In: ALBERTO, Armanda Álvaro. A Escola Regional de Meriti (Documentário) 1921- 1964. Rio de Janeiro: MEC-INEP-CBPE, 1968. p. 31.

BEZERRA, Nielson Rosa. As chaves da liberdade: estratégias de resistência escrava na ferrovia. Revista Pilares da História, Duque de Caxias: Instituto Histórico da Câmara Municipal de Duque de Caxias, Ano III, n. 4, p. 26-45, maio 2004.

BRITTO, Nara. Oswaldo Cruz: a construção de um mito na ciência brasileira. Rio de Janeiro: Fiocruz, 1995.

CAMPANTE, Délcio H. Metodismo e Setores Populares: estudo sobre a proposta de trabalho do Instituto Central do Povo (Rio de Janeiro. 1906-1930). 1985. Dissertação (Mestrado em Educação) - IESAE/FGV, Rio de Janeiro, 1985.

CARVALHO, Marta Maria C. de. Molde Nacional e Fôrma Cívica: higiene, moral e trabalho no projeto da Associação Brasileira de Educação (1924-1931). Bragança Paulista: EDUSF, 1998.

FERREIRA, Marieta de M. Em busca da idade de ouro: as elites políticas fluminenses na Primeira República (1889-1930). Rio de Janeiro: UFRJ, 1994. 
FERREIRA, Marieta de Moraes (org.). A República na Velha Província: oligarquias e crise no estado do Rio de Janeiro (1889-1930). Rio de Janeiro: Rio Fundo, 1989.

FORTE, José Mattoso Maia. Memória da Fundação de Iguassú: comemorativa do primeiro centenário da fundação da villa em 15 de janeiro de 1833. Rio de Janeiro: Typ. Do Jornal do Commércio, 1933.

FRÓES, Vânia. Município de Estrela (1846-1892). 1974. Dissertação (Mestrado em História) - Universidade Federal Fluminense, Niterói, 1974.

GÓES, Hildebrando de Araújo. Relatório apresentado pelo Engenheiro Chefe da

Comissão de Saneamento da Baixada Fluminense. Rio de Janeiro: Ministério da Viação e Obras Públicas, 1934.

HOCHMAN, Gilberto. A era do saneamento: as bases da política de saúde pública no Brasil. São Paulo: ANPOCS: HUCITEC, 1998.

LACOMBE, Laura J. Como nasceu o Colégio Jacobina. Rio de Janeiro: Soc. Graf. Vida Doméstica, 1962.

LEAL, Maria Cristina. Heitor Lyra da Silva. In: FÁVERO, Maria de Lourdes; BRITTO, Jader. Dicionário de Educadores no Brasil. 2. ed. Rio de Janeiro: UFRJ: MEC-INEP, 2002. p. 435440.

LIMA, Nísia T.; HOCHMAN, Gilberto. Condenado pela raça, absolvido pela medicina: O Brasil descoberto pelo movimento sanitarista da Primeira República. In.: MAIO, Marcos Chor; SANTOS, Ricardo Ventura. Raça, Ciência e Sociedade. Rio de Janeiro: Fiocruz: CCBB, 1996. p. 23-40.

LIMA, Nísia Trindade. Um sertão chamado Brasil: intelectuais e representação geográfica da identidade nacional. Rio de Janeiro: Revan: IUPERJ: UCAM, 1999.

LOURENÇO FILHO, Manuel B. Introdução ao Estudo da Escola Nova. 14. ed. Rio de Janeiro: EdUerj, 2002.

MAGALDI, Ana Maria. Lições de casa: discursos pedagógicos destinados à família no Brasil. Belo Horizonte: Argvmentvm: Faperj, 2007.

MENDONÇA, Edgar Sussekind. A Escola Regional de Meriti (realizações e projetos). In: ALBERTO, Armanda Álvaro. A Escola Regional de Meriti (Documentário) 1921- 1964. Rio de Janeiro: MEC-INEP-CBPE, 1968. p. 13-22.

MIGNOT, Ana Chrystina. Armanda Alberto. Recife: Fundação Joaquim Nabuco, Editora Massangana, 2010.

MIGNOT, Ana Chrystina. Baú de memórias, bastidores de histórias: o legado pioneiro de Armanda Álvaro Alberto. Bragança Paulista: EDUSF, 2002. 
NOFUENTES, Vanessa. Construindo a nação: liga contra o analfabetismo no Estado do Rio de Janeiro (1916-1919). XII ENCONTRO REGIONAL DE HISTÓRIA, 12., 2006. Anais [...]. Niterói: ANPUH: UFF, 2006.

NOVA IGUAÇU. De Iguassú a Nova Iguaçu: 170 anos (1833-2003). Textos de Ney Alberto e outros. Nova Iguaçu: Interanônima, 2003.

OLIVEIRA, C. A. Barbosa. A Escola Regional: aspectos urbano, rural, marítimo e fluvial. In: ALBERTO, Armanda Álvaro. A Escola Regional de Meriti (Documentário) 1921- 1964. Rio de Janeiro: MEC-INEP-CBPE, 1968. p. 95-105.

OLIVEIRA, Lúcia Lippi. A questão nacional na Primeira República. São Paulo: Brasiliense, 1990.

OLIVEIRA, Rafael da Silva. O ouro e o café na região de Iguaçu: da abertura de caminhos à implantação da estrada de ferro. Revista Pilares da História, Duque de Caxias: Instituto Histórico da Câmara Municipal de Duque de Caxias, Ano III, n. 4, p. 7-21, maio 2004.

PENNA, Belisário. Higiene e educação popular. In: ALBERTO, Armanda Álvaro. A Escola Regional de Meriti (Documentário) 1921- 1964. Rio de Janeiro: MEC-INEP-CBPE, 1968. p. 77-82.

PENNA, Belisário. Preleção de hygiene: conferência realizada na Escola regional de Merity, no dia 12 de julho de 1925, pelo Dr. Belisário Penna. Rio de Janeiro: [s.n.], 1925. Datilografado.

PENNA, Belisário. Relatório do Serviço de Profilaxia Rural, na região do estado do Rio de Janeiro limítrofe ao Distrito Federal, apresentado ao Presidente do Estado do Rio dr. Raul Veiga. Rio de Janeiro: [s.n.], 15 jul. 1920. Datilografado.

PENNA, Belisário. Saneamento do Brasil: sanear o Brasil é povoal-o; é enriquecel-o; é moralisal-o. Rio de Janeiro: Typ. Revista dos Tribunaes, 1918.

PENNA, Belisário. Solução de um problema vital: conferência do Dr. Belisário Penna, promovida pela Escola Regional de Meriti e realizada no Cine Meriti, no dia 12 de Julho de 1925. In: ALBERTO, Armanda Álvaro. A Escola Regional de Meriti (Documentário) 19211964. Rio de Janeiro: MEC-INEP-CBPE, 1968. p. 67-76.

PEREIRA, Waldick. Cana, café \& laranja. História econômica de Nova Iguaçu. Rio de Janeiro: FGV: SEEC-RJ, 1977.

PERES, Guilherme. Baixada Fluminense: os caminhos do ouro. Duque de Caxias: Gráfica Register, 1993.

REIS, Elisa Pereira. Poder Privado e construção de Estado na Primeira República. In: BOSCHI, R. (org.). Corporativismo e desigualdade: a construção do espaço público no Brasil. Rio de Janeiro: Rio Fundo: IUPERJ, 1991. 
SÁ, Dominichi Miranda de. A ciência como profissão: médicos, bacharéis e cientistas no Brasil (1895-1935). Rio de Janeiro: Fiocruz, 2006.

SÁ, Dominichi Miranda de. O Brasil "modelado" na obra de Belisário Penna (1916-1935). 1998. Dissertação (Mestrado em História Social) - IFCS, UFRJ, Rio de Janeiro, 1998.

SANTOS, Júlio Paixão. Cuidando do corpo e do espírito num sertão próximo: a experiência e o exemplo da Escola Regional de Meriti (1921-1932). 2008. Dissertação (Mestrado em História das Ciências e da Saúde) - Casa de Oswaldo Cruz, FIOCRUZ, Rio de Janeiro, 2008.

SILVA, André Felipe C. Nos meandros da medicina tropical: Arthur Neiva e os estudos sobre a malária (1906-1940). ENCONTRO REGIONAL DE HISTÓRIA, 12., 2006. Anais [...]. Niterói: ANPUH-RJ, 2006. p. 1-8.

SILVA, Rafael Freitas. O Rio antes do Rio. Rio de Janeiro: Babilônia Cultura Editorial, 2015.

SOUZA, Marlucia Santos de. Escavando o passado da cidade: história política da cidade de Duque de Caxias. Duque de Caxias: edição da autora, 2006.

STEPAN, Nancy. Gênese e evolução da ciência brasileira. Rio de Janeiro: Artenova, 1976.

VENÂNCIO FILHO, Alberto. Apresentação. In: ANDRADE, Olímpio de S. História e Interpretação de Os Sertões. 4. ed. rev. e aum. Rio de Janeiro: Academia Brasileira de Letras, 2002. p. XI-XVI. 